\title{
RANCANG BANGUN ALAT PENDETEKSI KEBOCORAN REGULATOR GAS LPG VIA SMS MENGGUNAKAN MODUL GSM DAN SENSOR MQ-6 BERBASIS ARDUINO UNO
}

\author{
Rivaldo Sirai, Kamil Erwansyah, Hendra Jaya, Hendryan Winata \\ Program Studi Sistem Komputer, STMIK Triguna Dharma \\ JI. A.H Nasution No.73 Medan, Sumatera Utara, 20142
}

\begin{abstract}
Abstrak
Kebocoran pada tabung atau instalasi gas merupakan salah satu risiko penggunaan Liquefied Petroleum Gas, apabila langkah penanggulangannya terlambat dan tidak tepat bisa mengancam keselamatan dan kesehatan. Kebocoran LPG tidak hanya rentan menyulut kebakaran atau ledakan bila terkena api, juga sangat berbahaya bagi kesehatan tubuh ketika terhirup, LPG memiliki karakteristik yang mudah terbakar serta memiliki berat jenis yang lebih besar dari udara sehingga sulit untuk mendeteksi gas tersebut apabila terjadi kebocoran pada tabung, yang disebabkan oleh gas ini, dikarenakan terakumulasi pada bagian bawah ruangan serta mudah terbakar, hal ini akan memiliki dampak yang lebih berbahaya apabila rumah sering ditinggal dalam kondisi regulator masih terpasang pada tabung.

Oleh karena itu dibuatlah system monitoring kebocoran gas menggunakan fitur tambahan yaitu Short Message Service, yang dapat mengirim pesan notifikasi ketika kebocoran pada LPG telah melewati batas normal yang dapat memicu terjadinya kebakaran yang dapat menelan korban.

Dengan demikian system monitoring kebocoran gas LPG ini dapat menginformasikan apabilah terdeteksi kebocoran gas LPG yang akan diberikan kepada pengguna melalui SMS (Short Message Service)
\end{abstract}

.Kata kunci : Kebocoran Gas, LPG,SMS, Monitoring

\begin{abstract}
Leakage of canisters or gas installations is one of the risks of using Liquefied Petroleum Gas, if the countermeasures are late and inappropriate can threaten safety and health. LPG leakage is not only prone to igniting fires or explosions when exposed to fire, it is also very dangerous for the health of the body when inhaled, LPG has flammable characteristics and has a larger type of air weight so it is difficult to detect the gas in the event of a leak in the tube, caused by this gas, due to the accumulation at the bottom of the room and flammable, this will have a more dangerous impact if the house is often left in the condition of regulators still attached to the tube. Therefore, a gas leak monitoring system is created using an additional feature, Short Message Service, which can send notification messages when the leak on lpg has crossed the normal limit that can trigger a fire that can engulf the victim.

Thus, this LPG gas leak monitoring system can inform if an LPG gas leak is detected that will be given to the user via SMS (Short Message Service)
\end{abstract}

Keywords : Kebocoran Gas, LPG,SMS, Monitoring

\section{PENDAHULUAN}

Liquefied Petroleum Gas (LPG) merupakan salah satu kebutuhan hidup manusia di zaman sekarang, peranan gas sangatlah penting bagi kehidupan manusia baik dalam rumah tangga 
maupun dalam dunia industri mengingat kebutuhan pangan sehari-hari yang tak luput dari penggunaan gas untuk memasak. [1] Gas LPG merupakan gas minyak bumi yang dicairkan dengan menambah tekanan dan menurunkan suhunya sehingga gas berubah menjadi cair. Minyak dan gas adalah sumber daya alam yang tidak dapat diperbarui apabila nantinya terus menerus digunakan maka akan habis. Namun tak jarang penggunaan gas malah memberikan dampak negatif bagi pengguna mengingat sebagian besar kebakaran diakibatkan oleh tabung gas yang bocor. Kebocoran pada tabung atau instalasi gas merupakan salah satu risiko penggunaan Liquefied Petroleum Gas (LPG), apabila langkah penanggulangannya terlambat dan tidak tepat bisa mengancam keselamatan dan kesehatan.

Kebocoran LPG tidak hanya rentan menyulut kebakaran atau ledakan bila terkena api, juga sangat berbahaya bagi kesehatan tubuh ketika terhirup, LPG memiliki karakteristik yang mudah terbakar serta memiliki berat jenis yang lebih besar dari udara sehingga sulit untuk mendeteksi gas tersebut apabila terjadi kebocoran pada tabung, yang disebabkan oleh gas ini, dikarenakan terakumulasi pada bagian bawah ruangan serta mudah terbakar karena adanya pengapian. Pada umumnya, kebocoran gas ini berasal dari kesalahan penggunaan regulator atau kerusakan pada valve (katup).

LPG. Selang bisa saja sudah rusak/getas, regulator pada katup tabung tidak terpasang benar/rusak, atau karet pengaman sudah rusak. Kebocoran gas ini sering kali terlambat dideteksi dan kerap tidak disadari karena kurangnya pengetahuan masyarakat tentang tandatanda kebocoran LPG. Adapun salah satu cara yang efektif untuk pencegahan dari dampak buruk kebocoran gas yang dapat menyebabkan kebakaran salah satunya adalah membuat system cerdas yang dapat mendeteksi adanya kebocoran pada tabung LPG yang nantinya dapat memberikan peringatan ketika tabung mengalami kebocoran serta dapat memberikan notifikasi berupa pesan yang dikirimkan melalui short message service (SMS), sistem ini juga dapat menambah keamanan apabila keadaan rumah sering ditinggal oleh pemilik rumah, atau ibu rumah tangga yang meninggalkan kompor gas dalam keadaan hidup karna mengurus anak. Sehingga apabila terjadi kebocoran maka system akan mengirimkan pesan singkat kepada pengguna dan membuat automatisasi pelepasan pada regulator ketika kebocoran gas sudah melampaui batas sehingga kebocoran akan terhenti, apabila sumber yang berasal dari regulator tabung LPG yang dapat memicu terjadinya kebakaran.

Untuk mendeteksi kebocoran gas LPG ini dapat menggunakan Arduino Uno dan sensor MQ6. [2] Sensor MQ6 adalah komponen yang dapat digunakan untuk mengkonversi suatu besaran tertentu menjadi satuan analog sehingga dapat dibaca oleh satuan elektronik. [3] oleh karena itu dibuatlah system monitoring kebocoran gas seperti pembahasan sebelumnya menggunakan fitur tambahan yaitu Short message service (SMS), yang dapat mengirim pesan notifikasi ketika kebocoran pada LPG telah melewati batas normal yang dapat memicu terjadinya kebakaran yang dapat menelan korban. [4] Penegertian Short Message Service (SMS) adalah kemampuan untuk mengirim dan menerima pesan dalam bentuk teks dari dan kepada perangkat mobile ponsel.

Dari permasalahan di atas penelitian ini bermaksud membuat sebuah sistem cerdas tertanam dengan ide penelitian "RANCANG BANGUN ALAT PENDETEKSI KEBOCORAN REGULATOR GAS LPG VIA SMS MENGGUNAKAN MODUL GSM DAN SENSOR MQ-6 BERBASIS ARDUINO UNO"

\section{METODE PENELITIAN}

Pada penelitian sistem kendali peralatan elektronik pada mobil truk ini disertakan metode penelitian yang dapat dilakukan mahasiswa pada pembuatan skripsi ini, yakni antara lain adalah sebagai berikut :

\section{Mengidentifikasi Masalah}

Pengidentifikasian masalah dalam penelitian ini adalah bagaimana agar dapat mengetahui kadar gas yang terdapat pada sekitar tabung Ipg.

2 Menganalisa Masalah

J-SISKO TECH Vol. 3, No. 2, 2020: 73-80 
Analisa pada penelitian ini adalah algoritma sistem dalam mengukur dan menginformasikan kepekatan kadar gas dengan menggunakan suatu metode dalam pengambilan keputusan.

\section{Menentukan Tujuan}

Menentukan tujuan yang akan di capai agar hasil yang diinginkan tidak jauh berbeda dengan yang diharapkan sebelumnya. Adapun dalam penelitian ini target yang dituju adalah mengimplementasikan sebuah metode sistematis ke dalam hardware mikrokontroler arduino yang dapat diterapkan ke dalam sistem serta dapat diterapkan ke dalam sistem nyata.

\section{Mempelajari Literatur}

Mempelajari sumber atau rujukan yang akan digunakan sebagai bahan referensi dalam penelitian ini. Beberapa jenis literatur yang di gunakan dalam penelitian ini adalah jurnal ilmiah dan buku tentang sensor dan arduino.

\section{Mendesain Sistem}

Dalam tahap ini data yang dikumpulkan akan di implementasikan ke dalam sistem hardware dengan penerapan algoritma yang telah di tentukan. Desain sistem ini berupa perencanaan dan perancangan prototype, serta pemilihan komponen yang digunakan sebagai bahan pengujian.

\section{Pengujian Sistem Hardware}

melakukan perancangan desain, selanjutnya dilakukan pengujian guna melihat hasil kerja alat apakah sesuai dengan yang diharapkan. Diawali dengan persiapan memberikan gas pada sensor Mq6 kemudian system akan mengirimkan informasi melalui sms dan kemudian akan membuka regulator pengamannan yang terpasang pada tabung LPG.

\section{Analisa Hasil}

Hasil yang didapat dari pengujian kemudian di analisa guna menentukan hasil yang akurat dan sesuia dengan yang diinginkan.

Kerangka Kerja



Gambar 1. Kerangka Kerja 
Berdasarkan gambar diatas maka dapat diuraikan langkah-langkah kerja penelitian sebagai berikut :

1.Mengidentifikasi Masalah

Masalah yang diidentifikasi dan dipecahkan dalam penelitian ini adalah kesulitan dalam mengimplementasikan metode sistem kedalam mikrokontroler, merancang sebuah prototype rancangan bangun sistem serta pengambilan keputusan hasil proses.

2.Menganalisa Masalah

Analisa yang dilakukan dalam penelitian ini adalah dalam hal menentukan peletakan sensor ultrasonik HC-SR05 sebagai media input-an pada sistem monitoring keamanan blind spot pada mobil truk.

3.Menentukan tujuan

Menentukan tujuan yang akan di capai agar hasil yang diinginkan tidak jauh berbeda dengan yang diharapkan sebelumnya. Adapun dalam penelitian ini target yang dituju adalah mengimplementasikan sebuah metode sistematis ke dalam hardware mikrokontroler arduino yang dapat diterapkan ke dalam sistem serta dapat diterapkan ke dalam sistem nyata.

\section{Mempelajari Literatur}

Mempelajari sumber atau rujukan yang akan digunakan sebagai bahan referensi dalam penelitian ini. Beberapa jenis literatur yang di gunakan dalam penelitian ini adalah jurnal ilmiah dan buku tentang sensor dan arduino.

\section{Mendesain Sistem}

Setelah perancangan sistem rancang bangun, tahap selanjutnya dilakukan tahap pengujian sistem rancang bangun. Hal ini dilakukan agar melihat hasil kinerja sistem baik dari segi rancang bangun sistem.

6.Menguji Sistem Hardware

Melakukan perancangan desain, selanjutnya dilakukan pengujian guna melihat hasil kerja alat apakah sesuai dengan yang diharapkan. Diawali dengan persiapan memberikan gas pada sensor Mq6 kemudian system akan mengirimkan informasi melalui sms dan kemudian akan membuka regulator pengamannan yang terpasang pada tabung LPG.8.Analisa Hasil

\section{Analisa Hasil}

Hasil yang didapat dari pengujian kemudian di analisa guna menentukan hasil yang akurat dan sesuia dengan yang diinginkan.

\section{ANALISA DAN HASIL}

PEMODELAN SISTEM DAN PERANCANGAN

\section{Flowchart}

Flowchart adalah suatu bagian yang menggambarkan urutan proses secara detail. Urutan ini menggambarkan cara kerja program serta aliran mulai (start) hingga selesai satu siklus kerja. Bagan ini bisa memberikan solusi selangkah demi selangkah untuk penyelesaian masalah yang ada didalam proses atau algoritma tersebut. Bagan alir logika program ini dipersiapkan oleh analis sistem. Bagan alir program komputer terinci (detailed computer program flowchart) digunakan untuk menggambarkan intruksi-intruksi program komputer secara terinci yang dipersiapkan oleh pemogram.




Gambar 2. Blok Diagram Sistem

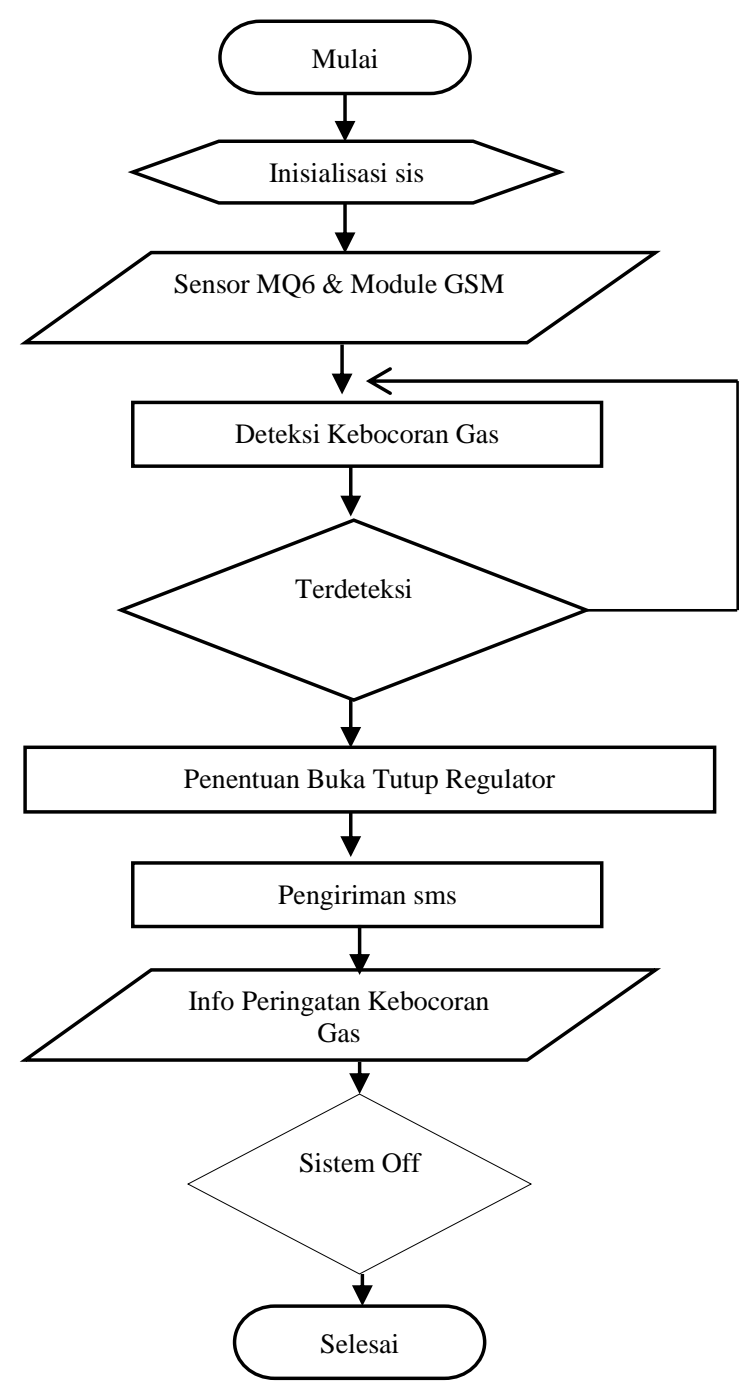

Gambar 3 Flowchart Sistem

2. Rangkaian Sistem

1. Arduino dan MQ6

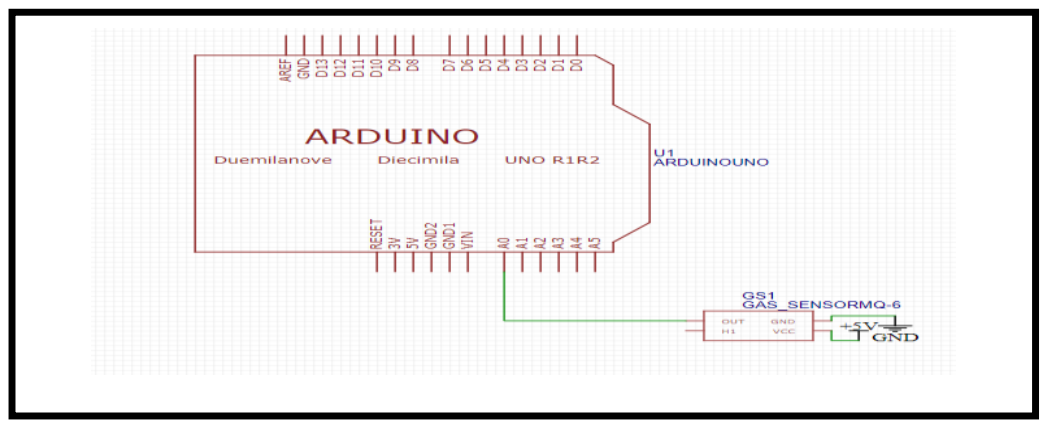


2. Module GSM

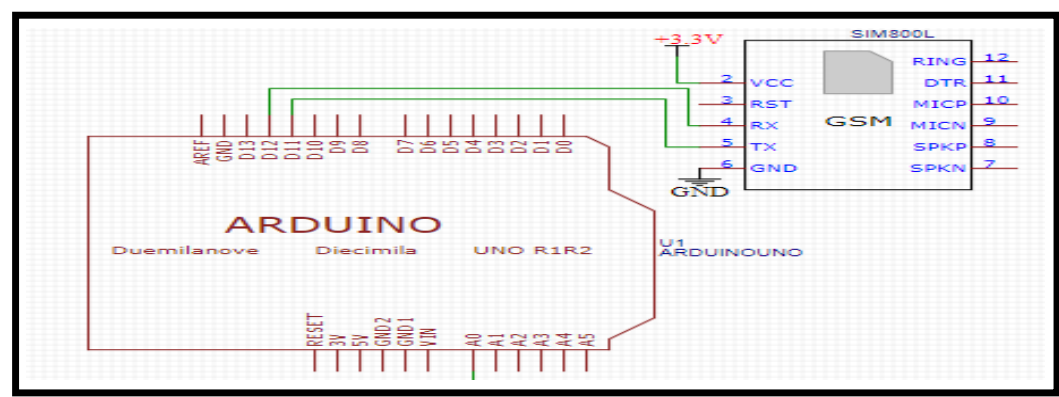

Gambar 5 Module GSM

3. Motor Servo

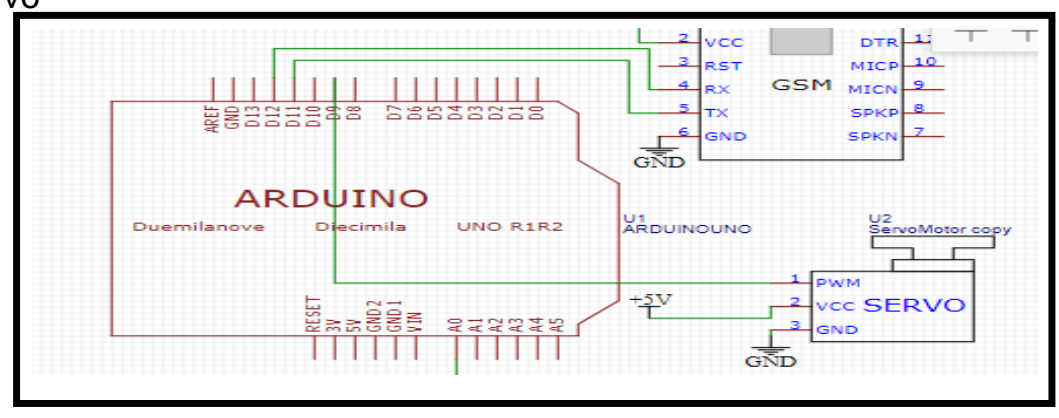

Gambar 6 Rangkaian Motor Servo

3. Pengujian Sistem

Setelah melakukan pengujian terhadap masing masing komponen pada sistem monitoring keamanan saat terjadi blind spot ini maka, selanjutnya dilakukanlah sebuah pengujian pada alat sistem ini yang mana untuk mengetahui apakah alat ini bekerja sesuai dengan yang diinginkan.

1. Pengujian Sistem

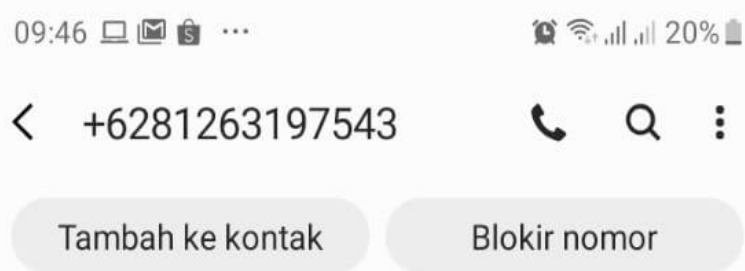

Kamis, 15 Agustus 2019

8 PERINGATAN!!!.... Ada Kebocoran Gas!!!

Gambar 7 Sistem Pada Saat Kebocoran Gas




Gambar 8 Sistem Servo Membuka Regulator



Gambar 9 Sistem Alarm dan LED Menyala

4. Kelebihan dan Kelemahan Sistem

Dalam perancangan atau pembuatan alat, pasti akan dijumpai kelebihan ataupun kekurangan dari alat yang dibangun. Kelebihan dan kekurangan tersebut adalah:

1. Membutuhkan arus catu daya yang lebih besar karena system menggunakan suplay motor penggerak, yang mengakibatkan bertambahnya pemakaian arus listrik PLN.

2. Sistem yang bergantung pada jaringan sim yang dipakai sistem, sehingga apabila jaringan tidak stabil maka kerja sistem akan terganggu.

3. Sistem memerlukan pulsa dan harus selalu melakukan pengecekan pulsa secara berkala agar tidak kehabisan pulsa yang menyebabkan gagalnya mengirim informasi peringatan pada smartphone.

5. Kelemahan Sistem

1. Sensor mQ6 didalam sistem lebih sensitive dan lebih responsive sehingga kebocoran gas dalam jumlah kecil dapat di deteksi secara efektif

2. Memiliki notif tambahan pada system yaitu alarm, sehingga memungkinkan pengguna atau orang disekitar mengetahui ada kebocoran gas .

3. Memiliki indicator led yang juga dapat menarik perhatian dan sebagai indicator ketika ada kebocoran gas dengan skala kecil.

\section{KESIMPULAN}

Berdasarkan hasil penelitian ini, dapat disimpulkan beberapa hal mengenai sistem keamanan kebocoran gas menggunakan teknik simplex.

1. Rancang bangun ini dirancang menggunakan sensor MQ6 sebagai deteksi gas yang nantinya akan diproses oleh arduino uno sehingga menghasilkan peringatan berupa pesan.

2. Untuk menerapkan komunikasi searah dalam memberikan peringatan kebocoran gas menggunakan modul GSM pada rancang bangun ini diterapkanlah teknik simplex yang akan bekerja berdasarkan input system sensor gas MQ6.

3. Penerapan motor servo digunakan saat sensor gas yang merupakan input mendeteksi adanya kebocoran kebakaran

\section{REFERENSI}

[1] I. Kurniaty and H. Hermansyah, "POTENSI PEMANFAATAN LPG (LIQUEFIED PETROLEUM GAS) SEBAGAI BAHAN BAKAR BAGI PENGGUNA KENDARAAN BERMOTOR," 2016.

[2] L. I. Ramadhan, D. Syauqy and B. H. Prasetio, "Sistem Pendeteksi Kebocoran Gas LPG 
Menggunakan Metode Fuzzy yang Diimplementasikan dengan Real Time Operating System (RTOS)," 2017.

[3] E. P. Zelvia, "KARAKTERISASI SENSOR GAS LIQUEFIED PETROLEUM GAS (LPG) DARI BAHAN SEMIKONDUKTOR HETEROKONTAK CUO/CUO(TIO2)," JIF), vol. 9, 2017.

[4] H. Setiadi, P. Alat, R. Ananda and M. Ardiansyah, "Perancangan Alat Pendeteksi Kebocoran Tabung Gas LPG Dengan Menggunakan Sensor MQ-6 Untuk Mengatasi Bahaya Kebakaran," 2019.

[5] M. Ferdian Putra, A. Harsa Kridalaksana, Z. Arifin and P. Studi Ilmu Komputer FKTI Universitas Mulawarman JI Barong Tongkok Kampus Gunung Kelua Kota Samarinda, "RANCANG BANGUN ALAT PENDETEKSI KEBOCORAN GAS LPG DENGAN SENSOR MQ-6 BERBASIS MIKROKONTROLER MELALUI SMARTPHONE ANDROID SEBAGAI MEDIA INFORMASI," Jurnal Informatika Mulawarman, vol. 12, no. 1, p. 1, 2017.

[6] Rizala, Abdul Muida* and Iklas Sanubarya, "Perbandingan Kinerja Sensor TGS2610, MQ2, dan MQ6 pada Alat Pendeteksi Kebocoran Tabung Liquified Petroleum Gas (LPG) Menggunakan ATMega2560," vol. 7, 2019.

[7] Adrian Simon Burhan1, Muljono1 and dan Eko Syamsuddin2, "ALAT PENCEGAHAN KEBAKARAN YANG DISEBABKAN KEBOCORAN LIQUEFIED PETROLEUM GAS (LPG)," vol. 15, 2018.

[8] [1]Rian Affrilianto, [2]Dedi Triyanto and [3]Suhardi, "RANCANG BANGUN SISTEM PELACAK KENDARAAN BERMOTOR MENGGUNAKAN GPS DENGAN ANTARMUKA WEBSITE," vol. 5, 2017.

[9] H. Amri and T. Elektro Politeknik Negeri Bengkalis JIn Bathin Alam Sungai Alam Bengkalis Riau, "Multitek Indonesia: Jurnal Ilmiah Sistem Monitoring Arus Dan Tegangan Menggunakan SMS Gateway," no. 13, pp. 1907-6223, 2019. 